\title{
STUDY ON THE NICKEL ADSORPTION CHARACTERISTICS OF LAKE SEDIMENTS AND SOIL
}

\author{
MA, X. ${ }^{\#}-$ SUN, J. ${ }^{1 \#}-$ REN, L. ${ }^{2 \#}-$ GUO, M. ${ }^{1}-$ WANG, Y. $.^{*}-$ HAN, X. ${ }^{1}$ \\ ${ }^{1}$ College of Resources and Environment, Jilin Agricultural University, 130118 Changchun, China \\ ${ }^{2}$ Hebei Puni Testing Technology Co., Ltd., 050011 Shijiazhuang, China \\ *Corresponding author \\ e-mail:951254609@qq.com; phone: 86-135-0441-9456 \\ ${ }^{\#}$ These authors contributed equally to this work \\ (Received $5^{\text {th }}$ Jun 2019; accepted $3^{\text {rd }}$ Sep 2019)
}

\begin{abstract}
The test adopted the OECD (Organisation for Economic Co-operation and Development) guideine106 equilibrium adsorption method (Bian et al., 2016), to explore the $\mathrm{Ni}$ adsorption behavior of the bottom sediment and black soil of the lake. The isothermal adsorption curve of $\mathrm{Ni}$ on sediment and black soil retained an "S" shape, and the Freundlich model and D-R model could sufficiently fit the adsorption of $\mathrm{Ni}$ by sediment and soil, and the correlation coefficient $\mathrm{r}$ was $0.9859 \sim 0.9963$; Within 120 min, the adsorption amount of nickel in the sediment and soil reached $99.57 \%$ and $99.84 \%$ of the total adsorption amount, respectively, and reached equilibrium after $720 \mathrm{~min}$. The final desorption amounts of $\mathrm{Ni}$ in sediments and soil accounting for $1.26 \%$ and $1.35 \%$ of the adsorption amounts, respectively. The amount of $\mathrm{Ni}$ adsorbed in the sediment increases with rising temperature, and the adsorption coefficient changes in the following manner: $\mathrm{K}_{\mathrm{f}} 15^{\circ} \mathrm{C}<\mathrm{K}_{\mathrm{f}} 25^{\circ} \mathrm{C}<\mathrm{K}_{\mathrm{f}} 35^{\circ} \mathrm{C}, \Delta \mathrm{G}<0$. The adsorption process of nickel on sediment and soil is spontaneous and high temperature is beneficial to this process. The removal of organic matter from sediment and soil weakened the adsorption of nickel, indicating that organic matter could improve the interception of nickel.
\end{abstract}

Keywords: sediment, soil, Ni, adsorption, desorption

\section{Introduction}

The content of nickel (Ni) on the earth ranks the fifth, and it generally exists in the form of ore in nature, and the $\mathrm{Ni}$ in the natural water body is basically in the form of sulfide and nitrate (Prithviraj et al., 2014). On October 27, 2017, the World Health Organization's International Agency for Research on Cancer announced that $\mathrm{Ni}$ is a class of carcinogen, which can lead to a variety of cancer lesions, such as rectal cancer, oral cancer (De Brouwere et al., 2012). Ni is non-biodegradable and persistent, and is easily enriched in soil and organisms, posing a serious threat to human health. In recent years, with the development of economy and society and the acceleration of industrialization, heavy metal pollution has become a global environmental pollution problem, especially the pollution of heavy metals to the soil environment (Kashulina et al., 2018; Abdelwaheb et al., 2017). A large amount of $\mathrm{Ni}$ is released into the environment through mining, atmospheric deposition, fertilizer and pesticide application, and sludge and sewage are irrigated into the soil. The Ni accumulated in the soil may remain in the soil and enter crops through planting and other agricultural activities, or enter water bodies through leaching. Part of the pollutants in the water will enter the sediment of the lake through the action of particle adsorption and sedimentation, which makes the sediment become the important "source" and "sink" of the pollutants, which will produce endogenous pollution. The sediment is an important part of the aquatic ecosystem. Heavy metal pollution can cause great harm to 
aquatic organisms, and thus cause harm to human body and ecosystem (Vukosav et al., 2014). Adsorption of soil and sediment can affect Ni mobility and bioavailability, thus playing a key role in reducing further risks to the environment and humans.

Riparian belt is a transition zone between land and river, and it is an important hub connecting aquatic ecosystem and terrestrial ecosystem. Human agricultural activities are the main source of sediment input to rivers. During rainstorms, a large amount of soil, silt and other materials are transported into rivers through surface runoff, so the sediment and the shore soil have a certain correlation on the components (Zhang et al., 2018). Therefore, it is necessary to study the adsorption characteristics of nickel in sediment and shore soil, and to understand the distribution law of metal nickel between solid and liquid phases. At present, there has been some research on the adsorption of $\mathrm{Ni}$ in soil, Sangiumsak (2014) investigates the adsorption of $\mathrm{Ni}$ and $\mathrm{Zn}$ on different kinds of soils found in the Northeastern Thailand as silty soil and sandy soil. Peng (2017) studied the adsorption and desorption characteristics of heavy metals in soil by soil organic matter and mineral composition, and found that SOM seems to play the most important role in soil adsorption of metal Ni. At present, there are many researches on soil adsorption of heavy metals, but few researches on the comparison between soil and sediment. This paper focuses on the evaluation of the adsorption potential of heavy metal nickel in sediments and soil, and provides theoretical guidance for the prevention of heavy metal contamination of groundwater in soil and sediment.

\section{Materials and methods}

\section{Samples for test}

\section{Sample collection and basic physical and chemical properties}

The tested sediment was taken from Xinlicheng reservoir, Changchun city, Jilin

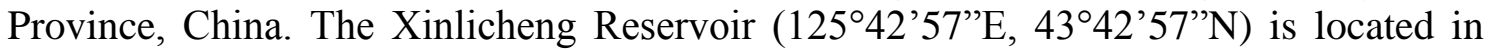
the middle and upper reaches of the Yitong River, $16 \mathrm{~km}$ from the center of Changchun. On May 24, 2017, grab dredger was used to collect the surface layer $(0-10 \mathrm{~cm})$ sediments of Xinlicheng reservoir. A sampling point was set at the upstream, middle and downstream of the reservoir, and repeated collection was made for three times. After the collected samples were mixed, and after air drying in the room, impurities such as animal and plant residues and stones were removed, and then ground through a 100 mesh sieve and stored for use (Duan et al., 2016). The tested soil was taken from the soil around the entrance of Xinlicheng reservoir. After removing the plants and rocks on the soil surface, five-point sampling method was used to collect the surface soil of $0 \sim 20 \mathrm{~cm}$ (Wu et al., 2017). The collected samples were naturally dried, removed animal and plant residues, stones and other impurities, and ground through a 100-mesh sieve for preservation. Sampling points are shown in Figure 1. The basic physical and chemical properties of samples were shown in Table 1.

Table 1. Physicochemical properties of test samples

\begin{tabular}{|c|c|c|c|c|c|c|c|c|c|}
\hline \multirow{2}{*}{ Sample } & \multirow{2}{*}{$\begin{array}{l}\text { Unit weight } \\
\quad\left(\mathbf{g} \cdot \mathbf{m}^{-3}\right)\end{array}$} & \multirow{2}{*}{$\begin{array}{c}\text { OM } \\
(\mathrm{g} / \mathrm{kg})\end{array}$} & \multirow{2}{*}{$\begin{array}{l}\text { TN } \\
(\%)\end{array}$} & \multirow{2}{*}{$\begin{array}{l}\mathbf{T P} \\
(\%)\end{array}$} & \multirow{2}{*}{$\begin{array}{c}\mathrm{Ni} \\
\left(\mathrm{mg}^{\mathrm{kg}} \mathrm{kg}^{-1}\right)\end{array}$} & \multicolumn{4}{|c|}{ Mechanical composition (\%) } \\
\hline & & & & & & Sand & Coarse silt & Fine silt & Clay \\
\hline & & & 0.1 & 0. & & 10. & 33 & & 31.43 \\
\hline Black soil & 1.65 & 34.65 & 0.12 & 0.09 & 21.10 & 4.84 & 51.43 & 22.96 & 20.77 \\
\hline
\end{tabular}




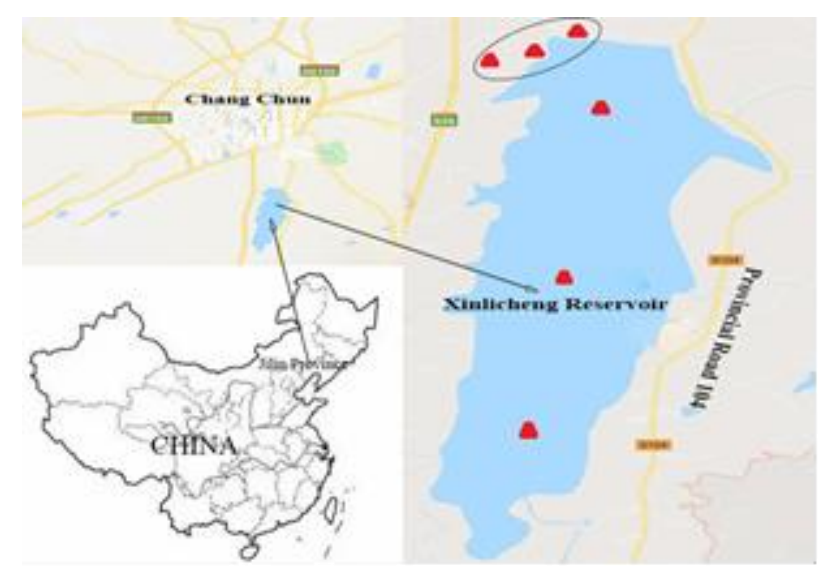

Figure 1. Schematic diagram of the location of Xinlicheng Reservoir in Changchun City, China

\section{Test design}

\section{Ni isotherm adsorption-desorption}

The experiment was conducted with reference to the OECD guideline106 equilibrium adsorption test (OECD). The $1.000 \pm 0.0005 \mathrm{~g}$ soil samples were taken in $50 \mathrm{ml}$ polyethylene centrifuge tubes, according to the water-soil ratio of 20:1, added $20 \mathrm{ml}$ solution containing different concentrations of $\mathrm{Ni}$ background, make the concentration of $\mathrm{Ni}$ respectively, 50, 100, 200,300, 400, $500 \mathrm{mg} \cdot \mathrm{L}^{-1}$, after shaking at a constant temperature at $25^{\circ} \mathrm{C}$ until adsorption equilibrium, it was centrifuged at $4000 \mathrm{r} \cdot \mathrm{min}^{-1}$ for $10 \mathrm{~min}$, filtered, and the concentration of $\mathrm{Ni}$ in the supernatant was measured. Immediately after the adsorption, the desorption test was carried out, after removing all the supernatant, added $20 \mathrm{ml}$ deionized water at $25^{\circ} \mathrm{C}$ under constant temperature oscillation to desorption balance, and the concentration of $\mathrm{Ni}$ in the supernatant was determined.

\section{Adsorption kinetics of $\mathrm{Ni}$}

According to the test method in $\mathrm{Ni}$ isothermal adsorption-desorption. Added $100 \mathrm{mg} \cdot \mathrm{L}^{-1} \mathrm{Ni}$ background solution $20 \mathrm{ml}$ for constant temperature oscillation at $25{ }^{\circ} \mathrm{C}$. Samples were taken at the time of 1, 5, 10, 20, 30, 60, 120, 240, 360, 480, 720 and $1440 \mathrm{~min}$, respectively, and centrifuged at $4000 \mathrm{r} \cdot \mathrm{min}^{-1}$ for $10 \mathrm{~min}$, then filtered and determined the Ni concentration in the supernatant.

\section{Ni adsorption thermodynamics}

According to the test method in $\mathrm{Ni}$ isothermal adsorption-desorption. Five Groups of $20 \mathrm{ml}$ solution with $\mathrm{Ni}$ concentration of $50,100,200,300,400$ and $500 \mathrm{mg} \cdot \mathrm{L}^{-1}$ were prepared, which were placed at $15{ }^{\circ} \mathrm{C}, 25{ }^{\circ} \mathrm{C}, 35^{\circ} \mathrm{C}$ constant temperature to oscillate to adsorption equilibrium, centrifuged at $4000 \mathrm{r} \cdot \mathrm{min}^{-1}$ for $10 \mathrm{~min}$, and filtered to determine the concentration of $\mathrm{Ni}$ in the supernatant.

\section{Effects of different organic matter contents on Ni adsorption behavior}

The organic matter in the sample was removed by $\mathrm{H}_{2} \mathrm{O}_{2}$ digestion method, and the experiment was conducted with reference to $\mathrm{Ni}$ adsorption thermodynamics. 
All tests were performed in triplicate.

Data processing

Freundlich equation:

$$
\lg q_{\varepsilon}=\lg K_{f}+\lg C_{\varepsilon}^{\frac{1}{n}}
$$

$\mathrm{D}-\mathrm{R}$ equation:

$$
\ln q_{\varepsilon}=\ln q_{m}-k \varepsilon^{2}
$$

Elovich equation:

$$
C=a+b \ln t
$$

Parabolic diffusion equation:

$$
\frac{c}{c_{N i}}=a+b t^{\frac{1}{2}}
$$

In Equation 1, $\lg \mathrm{K}_{\mathrm{f}}$ and $1 / \mathrm{n}$ respectively represent the adsorption capacity and adsorption strength of the sample to $\mathrm{Ni}$; In Equation 2, $\mathrm{q}_{\mathrm{m}}$ is the maximum adsorption capacity, $\mathrm{K}$ is a constant for the adsorption energy, $\varepsilon$ is the adsorption potential of Polanyi. In Equations 3 and 4: $\mathrm{C}_{\mathrm{Ni}}$ and $\mathrm{C}$ are the equilibrium adsorption capacity and the adsorption capacity at time $\mathrm{t}$, respectively $\mathrm{mg} \cdot \mathrm{kg}^{-1}$; $\mathrm{a}$ is the adsorption constant related to the maximum adsorption amount, and $\mathrm{b}$ is the adsorption rate coefficient, which is a measure of how fast the reaction rate decreases with time. $R$ value represents the correlation coefficient between variables in the sample, and the magnitude of correlation; $\mathrm{P}$ value is the test value, which is to test whether the two variables have the same correlation with the samples in the population from which the samples come, and $\mathrm{p}<0.01$ means extremely significant correlation.

\section{Results and discussion}

\section{Adsorption-desorption isothermal behavior of $\mathrm{Ni}$ in sediment and black soil and its discussion}

\section{Adsorption isotherm of $\mathrm{Ni}$ in sediment and black soil}

Adsorption isotherms of sediment and black soil on $\mathrm{Ni}$ are shown in Figure 2. It can be seen from Figure 2 that in the experimental concentration range, when the initial concentration of $\mathrm{Ni}$ changes from $50 \mathrm{mg} \cdot \mathrm{L}^{-1}$ to $500 \mathrm{mg} \cdot \mathrm{L}^{-1}$, the isothermal adsorption line of $\mathrm{Ni}$ in sediment and soil showed a tendency of increasing slope, but the adsorption amount did not reach saturation, When the concentration of $\mathrm{Ni}$ is $500 \mathrm{mg} \cdot \mathrm{L}^{-1}$, the equilibrium adsorption concentration of sediment and soil on $\mathrm{Ni}$ were 17.86 and $20.71 \mathrm{mg} \cdot \mathrm{L}^{-1}$, respectively, and the equilibrium adsorption amount were 9642.88 and $9585.84 \mathrm{mg} \cdot \mathrm{kg}^{-1}$ respectively. According to the classification of isothermal adsorption curves by Giles (1974), it can be seen that the isothermal adsorption curve of the sediment and soil to $\mathrm{Ni}$ is " $\mathrm{S}$ " type. For this " $\mathrm{S}$ " type isothermal adsorption line, the 
data can be analyzed and fitted with Freundlich and D-R models to explain the adsorption mechanism of $\mathrm{Ni}$ in sediment and soil, and the fitting parameters are shown in Table 2.

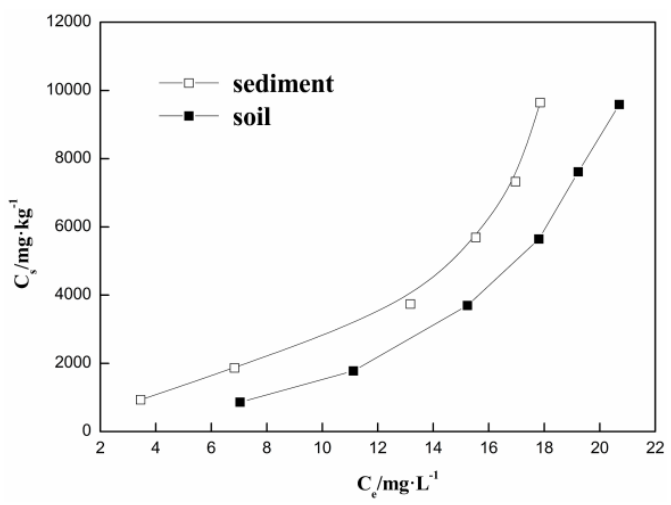

Figure 2. Adsorption isotherm of Ni in sediment and soil

Table 2. The isothermal adsorption fitting parameters of Ni in sediment and soil

\begin{tabular}{c|c|c|c|c|c|c}
\hline \multirow{2}{*}{ Sample type } & \multicolumn{3}{|c|}{ Freundlich equation } & \multicolumn{3}{c}{ D-R equation } \\
\cline { 2 - 7 } & $\boldsymbol{K}_{\boldsymbol{f}}$ & $\mathbf{1 / n}$ & $\boldsymbol{r}$ & $\boldsymbol{q}_{\boldsymbol{m}}$ & $\boldsymbol{k}$ & $\boldsymbol{r}$ \\
\hline Sediment & 3.1906 & 2.761 & $0.9891 * *$ & 31898.2507 & 68.8476 & $0.9859 * *$ \\
Soil & 1.2562 & 2.938 & $0.9963 * *$ & 26562.0806 & 78.3844 & $0.9866^{* *}$ \\
\hline
\end{tabular}

$\mathrm{n}=6, \mathrm{r}_{0.05}=0.811, \mathrm{r}_{0.01}=0.917$. **indicate statistical significance at $\mathrm{P}<0.01$. The same below

It can be seen from Table 2, Freundlich equation and D-R equation were used to fit the adsorption isotherms of nickel on sediment and soil, and the correlation coefficients were above 0.98 , the fitting results were all significantly correlated $(\mathrm{p}<0.01)$. The Freundlich equation has the best fitting effect, the adsorption constant $K_{\mathrm{f}}$ represents the adsorption capacity of $\mathrm{Ni}$ on the sediment and the soil. The larger of the $K_{\mathrm{f}}$, the stronger the adsorption capacity was. The adsorption coefficient $K_{\mathrm{f}}$ of $\mathrm{Ni}$ in the sediment was greater than that in the soil, indicating that the adsorption effect of the sediment on nickel was greater than that on the soil. When the concentration of nickel was lower than $500 \mathrm{mg} \cdot \mathrm{L}^{-1}$, the adsorption of $\mathrm{Ni}$ on sediments and soil did not reach the saturation state, which may be due to the modification effect of nickel on the bottom sediment and soil surface, forming a new adsorption field, thus promoting the adsorption of nickel in the bottom sediment and soil (Rinklebe et al., 2017). Since the D-R equation describes an ideal adsorption state in which the pores of an adsorbent are completely filled with solutes, the calculated equilibrium adsorption $q_{\mathrm{m}}$ is an ideal state.

\section{The desorption of Ni in sediment and black soil}

The desorption amount was often used as an index to indicate the adsorption strength, and can generally be used to illustrate the bonding degree of the colloidal surface active adsorption position with heavy metal ions (Tahervand et al., 2016, 2017). The desorption isotherm and desorption rate of $\mathrm{Ni}$ on bottom sediment and soil are shown in Figure 3. 


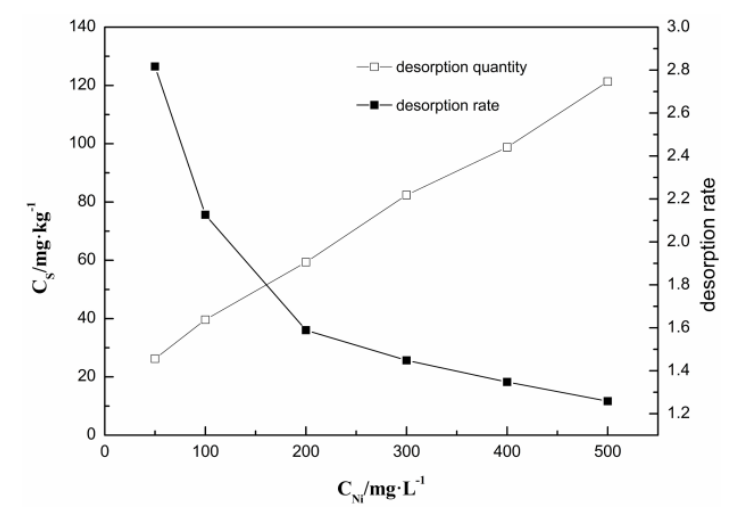

Figure 3. The desorption amount and desorption rate of Ni in sediment

As can be seen from Figure 4, the desorption of $\mathrm{Ni}$ by sediments and soil has a similar trend to that of adsorption, and the desorption of soil and sediment gradually increases with the increase of the initial $\mathrm{Ni}$ concentration. The final desorption of $\mathrm{Ni}$ by sediments and soil was $121.34 \mathrm{mg} \cdot \mathrm{kg}^{-1}$ and $129.78 \mathrm{mg} \cdot \mathrm{kg}^{-1}$, respectively, accounting for $1.26 \%$ and $1.35 \%$ of the adsorption capacity, respectively.

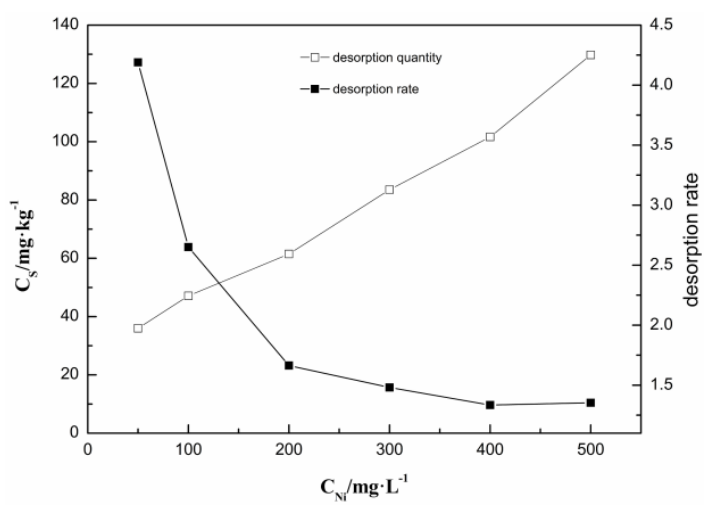

Figure 4. The desorption amount and desorption rate of $\mathrm{Ni}$ in soil

It can be seen that the adsorption capacity of sediments and soil to $\mathrm{Ni}$ was strong, while the desorption capacity was weak. The desorption amount of $\mathrm{Ni}$ in sediments was slightly less than that in soil. When the adsorption capacity was low, Ni occupies a high energy adsorption point, and the adsorption was mainly specific adsorption, so the desorption of Ni was difficult. When certain saturation was reached, specific adsorption points gradually decrease, and adsorption of heavy metals in stable sediments and soil was reduced, making it easier to desorption, so desorption also increased (Arancibia et al., 2015). The sediment contains more organic matter than the soil, so it has a stronger adsorption ability to nickel and a stronger fixation ability, leading to less desorption. Low Ni desorption may be the buffer of sediment and soil against heavy metal pollution (Davari et al., 2015). The desorption process can be regarded as the reverse process of soil adsorption process, and all factors affecting adsorption affect the desorption. The desorption data of $\mathrm{Ni}$ in sediment and soil are fitted with the Freundlich equation and the D-R equation, and the results are shown in Table 3. 
Table 3. Isothermal desorption fitting parameters of Ni in sediment and soil

\begin{tabular}{c|c|c|c|c|c|c}
\hline \multirow{2}{*}{ Sample type } & \multicolumn{3}{|c|}{ Freundlich equation } & \multicolumn{3}{c}{ D-R equation } \\
\cline { 2 - 7 } & $\boldsymbol{K}_{\boldsymbol{f}}$ & $\boldsymbol{n}$ & $\boldsymbol{r}$ & $\boldsymbol{q}_{\boldsymbol{m}}$ & $\boldsymbol{k}$ & $\boldsymbol{r}$ \\
\hline Sediment & 0.7218 & 0.5727 & $0.9706^{* *}$ & 197.7315 & 82.1164 & $0.9338^{* *}$ \\
Soil & 1.1054 & 0.6496 & $0.9724^{* *}$ & 151.2162 & 61.7417 & $0.9052^{* *}$ \\
\hline
\end{tabular}

$\mathrm{n}=6, \mathrm{r}_{0.05}=0.811, \mathrm{r}_{0.01}=0.917$

As can be seen from Table 3, the correlation coefficient of desorption isotherm of nickel in sediment and soil of Freundlich equation was 0.9937 0.9937, $K_{\mathrm{f}}$ (sediment) $<K_{\mathrm{f}}$ (soil). The adsorption capacity of sediment on $\mathrm{Ni}$ was strong, but its desorption capacity was weak. Ni adsorbed on sediments and soil is not easy to desorption. Kaur (2018) proposed to use hysteretic coefficient (HI) as a quantitative indicator of the irreversible adsorption degree of the compound in soil.

$$
\mathrm{HI}=\left(\mathrm{q}^{\mathrm{d}}-\mathrm{q}^{\mathrm{s}}\right) / \mathrm{q}^{\mathrm{s}}
$$

In the formula, $\mathrm{q}_{\mathrm{d}}$ and $\mathrm{q}_{\mathrm{s}}$ respectively refer to the adsorption concentration of $\mathrm{Ni}$ in the soil during adsorption and desorption at a certain temperature $\mathrm{mg} \cdot \mathrm{kg}^{-1}$. When $0.7<\mathrm{HI}<1.0$, the desorption rate was similar to the adsorption rate, and the adsorption isotherm coincides with the desorption isotherm. When $\mathrm{HI}<0.7$, the desorption rate was lower than the adsorption rate, and the desorption process was positive hysteresis. When $\mathrm{HI}>1.0$, the desorption process was negative hysteresis (Mosqueravivas et al., 2018). It can be seen from Table 4 that as the Ni concentration of the background solution increases, the desorption hysteresis coefficient gradually decreases and was much smaller than 0.7 , indicating that the desorption rate was much smaller than the adsorption rate. When the initial concentration was the same, HI sediment $<$ HI soil, indicating that the $\mathrm{Ni}$ adsorbed on the sediment was more difficult to desorption than the soil.

Table 4. Ni desorption hysteresis coefficient HI at different concentrations

\begin{tabular}{c|c|c|c|c|c|c}
\hline Initial concentration $(\mathbf{m g} / \mathbf{L})$ & $\mathbf{5 0}$ & $\mathbf{1 0 0}$ & $\mathbf{2 0 0}$ & $\mathbf{3 0 0}$ & $\mathbf{4 0 0}$ & $\mathbf{5 0 0}$ \\
\hline Sediment & 0.0290 & 0.0217 & 0.0161 & 0.0147 & 0.0131 & 0.0127 \\
Soil & 0.0437 & 0.0273 & 0.0169 & 0.015 & 0.0135 & 0.0137 \\
\hline
\end{tabular}

\section{Adsorption kinetics of $\mathrm{Ni}$ in sediment and black soil}

The change of Ni adsorption amount with sediment and black soil with time is shown in Figure 5. As can be seen from Figure 5, the whole adsorption process can be divided into two stages, namely, rapid adsorption stage and slow equilibrium stage. The concentration of $\mathrm{Ni}$ in the solution decreased rapidly in $0-120 \mathrm{~min}$, and the concentration of $\mathrm{Ni}$ in the solution was gradually balanced in the 120-1440 min solution. In the 0-120 min, the adsorption amount of $\mathrm{Ni}$ to the sediment and soil accounted for $99.57 \%$ and $99.84 \%$ of the total adsorption, respectively. At the adsorption equilibrium, the maximum adsorption capacity of sediment and soil to $\mathrm{Ni}$ was 1881.60 and $1804.58 \mathrm{mg} \cdot \mathrm{kg}^{-1}$. Because there are more adsorption sites on the 
surface of the sediment and soil, Ni can be quickly adsorbed. When more and more adsorption sites are occupied, the reaction rate decreases until the adsorption reaches equilibrium. Ni may form a complex when adsorbed in the sediment and soil, so that the heavy metals adsorbed on its appearance are transferred to the inside of the particles and precipitate on the sediment and soil surface, so that the adsorption of the sediment and soil to the Ni was getting smaller, and finally until it tended to balance (Peng et al., 2018). And the reduction agent in the sediment and soil dissolves from the solid phase to the water phase is a slow dissolution process (Huang et al., 2018).

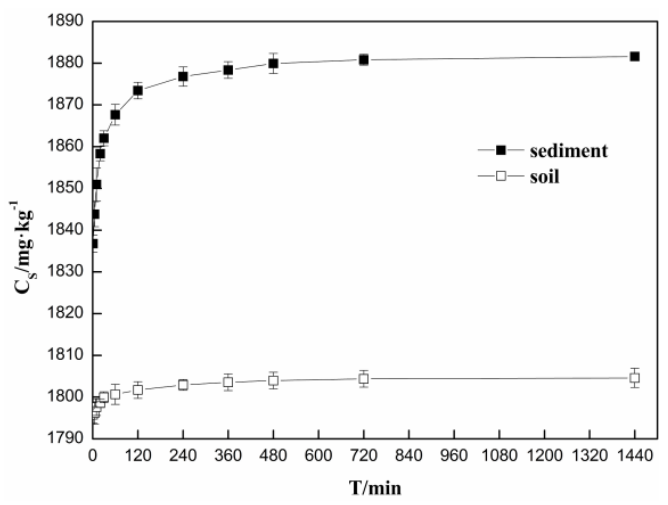

Figure 5. The adsorption kinetic curve of $\mathrm{Ni}$

In this experiment, Elovich equation and parabolic diffusion equation were used to fit the adsorption kinetics of $\mathrm{Ni}$ in sediment and black soil. The relevant parameters of the fitting are shown in Table 5. It can be seen from Table 5 that Elovich equation has a good fitting effect on the adsorption kinetics of $\mathrm{Ni}$ in sediments and black soil, indicating that the adsorption kinetics process is non-uniform diffusion process, and the reaction process is controlled by multiple mechanisms such as diffusion, dissolution and mineralization. The adsorption fitting coefficient $\mathrm{r}$ of $\mathrm{Ni}$ in lake bottom sediment and soil was 0.9827 and 0.9895 , respectively. The greater the constant a value in the Elovich equation, the greater the adsorption rate, so the adsorption amount of the sediment is greater than the adsorption amount of the soil. The fitting of adsorption by parabolic diffusion equation is relatively poor, and the correlation coefficients $r$ were 0.7905 and 0.8813 , respectively. In the above model fitting, it can be inferred that the diffusion of particles is not the only mechanism controlling the adsorption process, which is also adsorbed by other adsorbents (Zhu et al., 2015).

\section{Adsorption thermodynamics of Ni in sediment and black soil}

The adsorption of $\mathrm{Ni}$ by sediment and black soil over time are shown in Figures 6 and 7. As can be seen from Figures 6 and 7, in the test temperature range, with the increase of temperature, the adsorption amount of sediment and soil to $\mathrm{Ni}$ increases gradually, and the adsorption does not reach saturation. The increase of temperature was beneficial to the adsorption of $\mathrm{Ni}$ by sediment and soil, and the reaction can be determined to be an endothermic reaction. Heavy metal $\mathrm{Ni}$ has good hydration in the test temperature range. When the metal Ni was adsorbed by sediment and soil, it lost its hydrating shell. The process of nickel losing hydrated shell requires some energy, and the process of removing water molecules is endothermic. The higher the temperature is, 
the more favorable it is for the Ni adsorbed on the bottom sediment and soil surface to diffuse into the particles. It is also a benefit for external complexity and internal complexity. It also facilitates the combination of thermodynamic unstable state to stable state transition. Therefore, the adsorption of nickel in sediments and soil increases with temperature.

Table 5. Parameters of the kinetics adsorption models for Ni in sediment and black soil

\begin{tabular}{c|c|c|c|c|c|c|c}
\hline \multirow{2}{*}{ Soil type } & \multicolumn{3}{|c|}{ Elovich equation } & \multicolumn{4}{c}{ Parabolic diffusion equation } \\
\cline { 2 - 8 } & $\mathbf{a}$ & $\mathbf{b}$ & $\mathbf{r}$ & $\mathbf{a}$ & $\mathbf{b}$ & $\mathbf{s}$ & $\mathbf{r}$ \\
\hline Sediment & 1836.8507 & 6.8847 & $0.9827^{* *}$ & 293.8471 & 0.1789 & 6.3016 & $0.7905^{* *}$ \\
Black soil & 1795.5288 & 1.2942 & $0.9895^{* *}$ & 267.2892 & 0.0346 & 6.7273 & $0.8813^{* *}$ \\
\hline
\end{tabular}

$\mathrm{n}=12, \mathrm{r}_{0.05}=0.0 .576, \mathrm{r}_{0.01}=0.708$

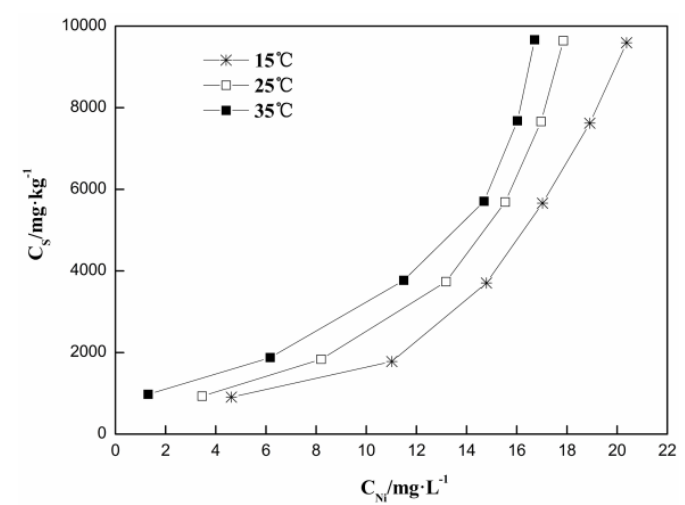

Figure 6. The effect of different temperature on the adsorption of Ni in the sediment

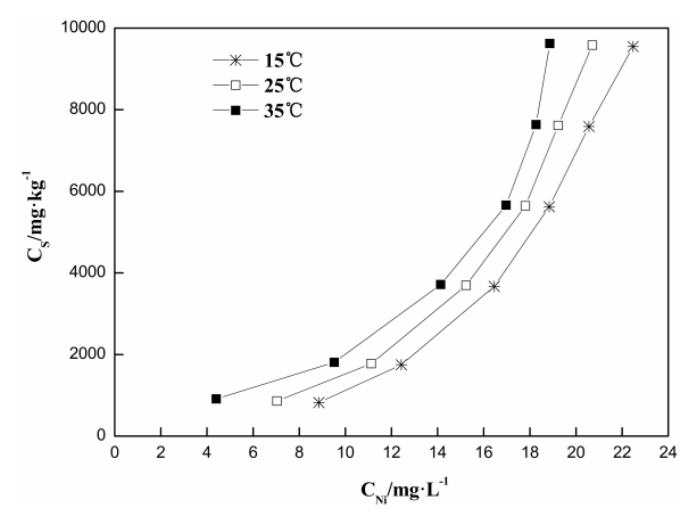

Figure 7. The effect of different temperature on the adsorption of $\mathrm{Ni}$ in the soil

When the temperature at $15{ }^{\circ} \mathrm{C}, 25^{\circ} \mathrm{C}$ and $35^{\circ} \mathrm{C}$ sediment and soil on the adsorption thermodynamics equation of $\mathrm{Ni}$ fitting results as shown in Table 6. The adsorption thermodynamics of sediment and soil on $\mathrm{Ni}$ is well correlated with the thermodynamic fitting of $\mathrm{Ni}$ on sediment and soil. The coefficient $R$ is between 0.9491 and 0.9975 . Sediment and soil on the adsorption of Ni coefficient $K_{\mathrm{f}} 15^{\circ} \mathrm{C}<K_{\mathrm{f}} 25^{\circ} \mathrm{C}<K_{\mathrm{f}} 35^{\circ} \mathrm{C}$, show 
that the higher the temperature, the stronger the adsorption capacity of sediment and soil nickel. The adsorption reaction can be determined as endothermic reaction.

Table 6. The isotherm adsorption parameters of Ni at different temperatures

\begin{tabular}{c|c|c|c|c|c|c|c}
\hline \multirow{2}{*}{$\begin{array}{c}\text { Sample } \\
\text { type }\end{array}$} & $\begin{array}{c}\text { Temperature } \\
\left({ }^{\circ} \mathrm{C}\right)\end{array}$ & \multicolumn{3}{|c|}{ Freundlich equation } & \multicolumn{3}{c}{ D-R equation } \\
\cline { 3 - 8 } & 15 & $\boldsymbol{K}_{\boldsymbol{f}}$ & $\boldsymbol{n}$ & $\boldsymbol{r}$ & $\boldsymbol{q}_{\boldsymbol{m}}$ & $\boldsymbol{k}$ & $\boldsymbol{r}$ \\
\hline \multirow{4}{*}{ Sediment } & 25 & 3.9583 & 0.3554 & $0.9923 * *$ & 24814.9828 & 70.5966 & $0.9786^{* *}$ \\
& 35 & 17.0777 & 0.4513 & $0.9617 * *$ & 21947.8305 & 44.4613 & $0.9246^{* *}$ \\
\hline \multirow{3}{*}{ Soil } & 15 & 1.0453 & 0.3419 & $0.9829 * *$ & 25954.7285 & 88.6074 & $0.9832 * *$ \\
& 25 & 1.2568 & 0.3406 & $0.9946^{* *}$ & 26562.0767 & 78.3846 & $0.9723 * *$ \\
& 35 & 1.4630 & 0.3384 & $0.9724 * *$ & 27134.1593 & 69.9409 & $0.9438^{* *}$ \\
\hline
\end{tabular}

$\mathrm{n}=6, \mathrm{r}_{0.05}=0.811, \mathrm{r}_{0.01}=0.917$

According to the $K_{\mathrm{f}}$ in the Freundlich equation at different temperatures, the enthalpy change and entropy change are calculated by $\ln K_{\mathrm{f}}$ and $1 / \mathrm{T}, \Delta G=\Delta H-T \Delta S$. It can be seen from Table 7 that the $\Delta G$ at different temperatures were less than zero, as the rise of environmental temperature, $\Delta G$ gradually reduced. It was indicated that the adsorption process of $\mathrm{Ni}$ on sediment and soil is spontaneous, and the high temperature is favorable for the spontaneity of adsorption, which is consistent with the fitting results of Langmuir equation and Freundlich equation (Wu et al., 2013; Turp, 2018). It can be seen from the table that $\Delta H>0$ of $\mathrm{Ni}$ in the sediment and soil is indicated as an endothermic reaction. $\Delta G$ and $\Delta H$ indicated that sediment and soil buffer capacity of $\mathrm{Ni}$, and may have a seasonal migration and activity (Guo et al., 2012).

Table 7. The thermodynamic parameters of Ni in sediment and soil

\begin{tabular}{c|c|c|c|c}
\hline Sample type & $\begin{array}{c}\text { Temperature } \\
{ }^{\circ} \mathrm{C}\end{array}$ & $\begin{array}{c}\boldsymbol{\Delta G} \\
\mathbf{K J} \cdot \mathbf{m o l}^{\mathbf{1}}\end{array}$ & $\begin{array}{c}\boldsymbol{\Delta H} \\
\mathbf{K J}^{\mathbf{m}} \mathbf{\mathbf { m o l } ^ { - 1 }}\end{array}$ & $\begin{array}{c}\boldsymbol{\Delta S} \\
\mathbf{K J} \cdot(\mathbf{m o l} \cdot \mathbf{K})^{-\mathbf{1}}\end{array}$ \\
\hline \multirow{3}{*}{ Sediment } & 15 & -1.1707 & & \\
& 25 & -3.9703 & 79.5104 & 0.2804 \\
& 35 & -6.7706 & & \\
\hline \multirow{3}{*}{ Soil } & 15 & -0.2308 & & \\
& 25 & -0.6704 & 12.4508 & 0.0403 \\
& 35 & -1.1102 & & \\
\hline
\end{tabular}

\section{Effect of organic matter content on adsorption characteristics of $\mathrm{Ni}$}

The Ni adsorption by sediment and soil before and after the removal of organic matter are shown in Figures 8 and 9. As can be seen from the figure, when organic matter was removed from sediments and soil, and the Ni concentration in the solution was $500 \mathrm{mg} \cdot \mathrm{L}^{-1}$, the adsorption capacity of sediments and soil on $\mathrm{Ni}$ decreased by $2.17 \%$ and $1.7 \%$, respectively. The above phenomenon indicates that the presence of organic matter can increase the adsorption of $\mathrm{Ni}$ by sediment and soil. In the experiment, according to the formula of: contribution rate $=\left(Q_{\text {original }}-Q_{\text {removal }}\right) / Q_{\text {removal }}$. According to this formula, the contribution rate of organic matter in sediment and soil to 
Ni was $2.06 \%$ and $1.73 \%$ respectively. The higher the content of organic matter is, the greater the contribution rate of organic matter to $\mathrm{Ni}$ was, and the adsorption point of sediment to $\mathrm{Ni}$ after removing organic matter is greater than that of soil.

There was a significant correlation between the adsorption amount and the content of organic matter. The reason may be that the organic matter entered the sediments and soil to form humus after microbial action. Humus contains carboxyl, phenol hydroxyl and alcohol hydroxyl. These groups can easily complex or chelate with heavy metal elements to form stable compounds, thus improving their adsorption capacity. In addition, polar groups in sediment and soil organic matter, such as hydroxyl group and carboxyl group, can make sediment and soil surface have a large amount of negative charge, thus enhancing the electrostatic adsorption of nickel (Refaey et al., 2014; Yin et al., 2016).

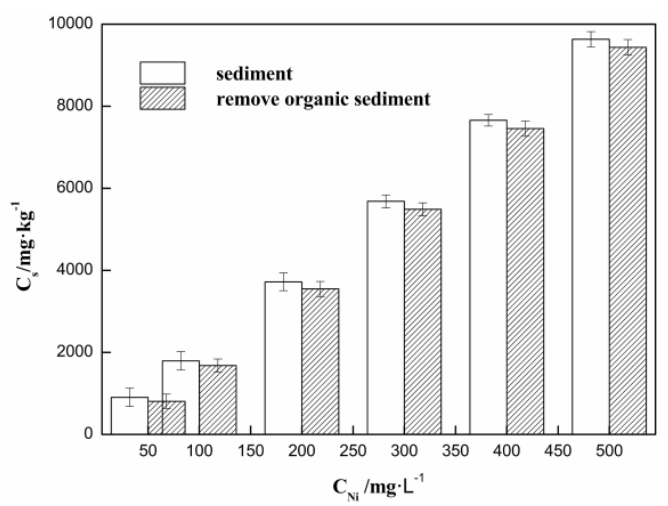

Figure 8. Adsorption isotherm of Ni under removal of sediment organic before and after

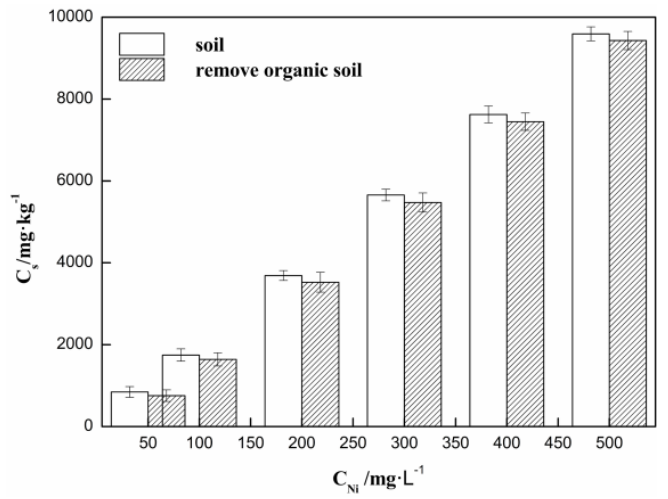

Figure 9. Adsorption isotherm of Ni under removal of soil organic before and after

\section{Conclusion}

The adsorption characteristics of $\mathrm{Ni}$ on the sediment of the lake and the black soil on the shore show that the adsorption of $\mathrm{Ni}$ on the sediment was larger than that in the soil, and the adsorption process can be fitted with the Freundlich model and the D-R model. The Freundlich model can better fit the adsorption of $\mathrm{Ni}$ by sediment and soil. The correlation coefficient $\mathrm{r}$ were 0.9891 and 0.9963 , the final desorption amount of sediment and soil to $\mathrm{Ni}$ are 121.34 and $129.78 \mathrm{mg} \cdot \mathrm{kg}^{-1}$, which accounts for $1.26 \%$ and $1.35 \%$ of adsorption, respectively. The initial concentration was the same, 
$\mathrm{HI}_{\text {sediment }}<\mathrm{HI}_{\text {soil }}$, indicated that the sediment had a stronger retention capacity to $\mathrm{Ni}$ than the soil. The adsorption kinetics of nickel in sediments and black soil can be well fitted by Elovich equation. In the experimental temperature range, the adsorption amount of $\mathrm{Ni}$ on the sediment and soil gradually increased with the increase of temperature, and the $\Delta G$ value of adsorption thermodynamic parameters is less than 0 , which indicates that $\mathrm{Ni}$ adsorption process on sediment and shore soil is spontaneous. After removing organic matter, the adsorption capacity of bottom sediment and soil on $\mathrm{Ni}$ was weakened, and the adsorption capacity was reduced by $2.02 \%$ and $1.70 \%$, respectively, indicating that organic matter could enhance the retention capacity of $\mathrm{Ni}$. These factors may limit or enhance the transport or absorption of metal Ni in soil. This work provides a theoretical framework for the prediction of metal adsorption characteristics and provides a potential help for the prediction of bioavailability, fate and transport of heavy metals in newly contaminated areas. Meanwhile, the interaction between $\mathrm{Ni}$ and other heavy metals is expected to be considered in future studies.

\section{REFERENCES}

[1] Abdelwaheb, M., Dridi-Dhaouadi, S. (2017): Impact of soil properties on groundwater contamination risks by nickel and lead. - Euro-Mediterranean Conference for Environmental Integration, 22-25 November 2017, Sousse, Tunisia.

[2] Arancibia-Miranda, Nicolás, Silva-Yumi, J., Escudey, M. (2015): Effect of cations in the background electrolyte on the adsorption kinetics of copper and cadmium and the isoelectric point of imogolite. - Journal of Hazardous Materials S0304389415006263.

[3] Bian, W., Ma, X., Wang, F., Zhang, L., Ren, L., Wang, Y. (2016): Study on the adsorption characteristics of ciprofloxacin in saline alkali soil. - Acta Agroenvironmental Sinica 35(10): 1953-1959.

[4] Davari, M., Rahnemaie, R., Homaee, M. (2015): Competitive adsorption-desorption reactions of two hazardous heavy metals in contaminated soils. - Environmental Science \& Pollution Research 22(17): 13024-13032.

[5] De Brouwere, K., Buekers, J., Cornelis, C., Schlekat, C. E., Oller, A. R. (2012): Assessment of indirect human exposure to environmental sources of nickel: oral exposure and risk characterization for systemic effects. - Science of the Total Environment 419(0): 25-36.

[6] Duan, Q., Lee, J., Liu, Y., et al. (2016): Distribution of heavy metal pollution in surface soil samples in China: a graphical review. - Bulletin of Environmental Contamination and Toxicology 97(3): 303-309.

[7] Guo, P., Yang, L. I., Zhang, Y. X., Ming, L., Zhang, S., Yue-Ming, L. I. (2012): Effect of freeze-thaw on the adsorption of heavy metals by soil. - Journal of Jilin University 2012(3).

[8] Huang, L., Jin, Q., Tandon, P., Li, A., Du, J. (2018): High-resolution insight into the competitive adsorption of heavy metals on natural sediment by site energy distribution. Chemosphere 197: 411.

[9] Kashulina, G. M. (2018): Monitoring of soil contamination by heavy metals in the impact zone of copper-nickel smelter on the Kola Peninsula. - Eurasian Soil Science 51(4): 467478.

[10] Kaur, P., Kaur, P. (2018): Time and temperature dependent adsorption-desorption behaviour of pretilachlor in soil. - Ecotoxicology \& Environmental Safety 161: 145.

[11] Mosqueravivas, C. S., Martinez, M. J., GarcíaSantos G., Guerrerodallos, J. A. (2018): Adsorption-desorption and hysteresis phenomenon of tebuconazole in Colombian agricultural soils: experimental assays and mathematical approaches. - Chemosphere 190(2): 393-404. 
[12] Peng, L., Liu, P., Feng, X., Wang, Z., Cheng, T., Liang, Y. (2018): Kinetics of heavy metal adsorption and desorption in soil: developing a unified model based on chemical speciation. - Geochimica et Cosmochimica Acta 224: 282-300.

[13] Prithviraj, D., Deboleena, K., Neelu, N. (2014): Biosorption of nickel by Lysinibacillus sp. BA2 native to bauxite mine. - Exotoxicology and Environmental Safety 107(0): 260268.

[14] Refaey, Y. B., Jansen, B., Elshater, A. H., Elhaddad, A. A., Kalbitz, K. (2014): The role of dissolved organic matter and its adsorption for the fate of heavy metals in clay-rich soil. - Abstracts of the EGU General Assembly Conference Vienna, Austria, 27 April-02 May, 2014.

[15] Rinklebe, J., Shaheen, S. M. (2017): Redox chemistry of nickel in soils and sediments: a review. - Chemosphere 179: 265-278.

[16] Sangiumsak, N., Punrattanasin, P. (2014): Behaviors of ni and zn adsorption on different soils found in the northeastern Thailand. - Advanced Materials Research 931-932: 681686.

[17] Tahervand, S., Jalali, M. (2016): Sorption, desorption, and speciation of Cd, Ni, and Fe by four calcareous soils as affected by $\mathrm{pH}$. - Environmental Monitoring \& Assessment 188(6): 1-12.

[18] Tahervand, S., Jalali, M. (2017): Sorption and desorption of potentially toxic metals (Cd, $\mathrm{Cu}, \mathrm{Ni}$ and $\mathrm{Zn}$ ) by soil amended with bentonite, calcite and zeolite as a function of $\mathrm{pH}$. Journal of Geochemical Exploration 181. DOI: 10.1016/j.gexplo.2017.07.005.

[19] Turp, S. M. (2018): $\mathrm{Mn}^{2+}$ and $\mathrm{Cu}^{2+}$ adsorption with a natural adsorbent: expanded perlite. - Applied Ecology and Environmental Research 16(4): 5047-5057.

[20] Vukosav, P., Mlakar, M., Cukrov, N., Željko Kwokal, Pižeta, I., Pavlus, N., et al. (2014): Heavy metal contents in water, sediment and fish in a karst aquatic ecosystem of the Plitvice Lakes National Park (Croatia). - Environmental Science \& Pollution Research 21(5): 3826-3839.

[21] Wu, F., Liu, H., Zhang, M., Ma, W., Huang, X., Liu, S., et al. (2017): Adsorption characteristics and the effect of dissolved organic matter on mercury (ii) adsorption of various soils in china. - Journal of Soil Contamination 26(2): 14.

[22] Wu, Y., Yilihan, P., Cao, J., Jin, Y. (2013): Competitive adsorption of Cr (VI) and Ni (II) onto coconut shell activated carbon in single and binary systems. - Water, Air, \& Soil Pollution 224(9): 1662.

[23] Yin, B., Zhou, L., Yin, B., Liang, C. (2016): Effects of organic amendments on rice (Oryza sativa L.) growth and uptake of heavy metals in contaminated soil. - Journal of Soils \& Sediments 16(2): 537-546.

[24] Zhang, L., Duff, A., Smith, C. J. (2018): Community and functional shifts in ammonia oxidizers across terrestrial and marine (soil/sediment) boundaries in two coastal bay ecosystems. - Environmental Microbiology 20(8).

[25] Zhu, D. N., Zou, S. Z., Zhou, C. S. (2015): Adsorption characteristics of $\mathrm{Cd}^{2+}$ in typical soils in karst areas. - China Karst 34(4). 